\title{
Current Evidence's on Basic Emergency Obstetric and Newborn Care in Primary Health Care unit of Gedeo zone, South Ethiopia, 2018
}

\author{
Rekiku Fikre $^{1 *}$ and Muntasha Berhanu ${ }^{2}$ \\ ${ }^{1}$ Department of midwifery, Ethiopia \\ ${ }^{2}$ Department of public health, Ethiopia
}

*Corresponding author: Rekiku Fikre (BSc in Midwifery, M.sc in Maternity and Reproductive Health): college of medicine and health sciences, Department of midwifery, Dilla, Ethiopia

\begin{abstract}
ARTICLE INFO
Received: 幽 April 15, 2019

Published: 幽 April 25, 2019

Citation: Rekiku Fikre, Muntasha Berhanu. Current Evidence's on Basic Emergency Obstetric and Newborn Care in Primary Health Care unit of Gedeo zone, South Ethiopia, 2018. Biomed J Sci \& Tech Res 17(3)-2019. BJSTR. MS.ID.003005.
\end{abstract}

Keywords: Emergency; Obstetrics; Newborn care

Abbreviations: AMSTIL: Active Management of Third Stage of Labour; EmONC: Emergency Obstetrics and Newborn Care; HR: Human Resource; PHC: Primary Health Care Facilities; MDGs: Milliunm Development Goals; SBAs: Skilled Birth Attendants; SSA: Sub-Sahra Africa; SNNPR: South Nation Nationality and People; WHO: World Health Organization

\section{ABSTRACT}

Background: Worldwide life-threatening complications during pregnancy, accounts $15 \%$ of expected births. However basic emergency obstetric and newborn cares prevent $40 \%$ of intrapartum related neonatal deaths and maternal mortality. Providers skilled in emergency obstetric and newborn care (EmONC) services are essential, particularly in countries with a high burden of maternal and newborn mortality. Therefore, the purpose of this study is to assess the situation on current evidence on EmONC in primary health care unit of Gedeo zone, SNNPR, 2017.

Method: A facility based cross-sectional assessment was conducted in twenty randomly selected primary health care facilities from six Woreda of Gedeo zone in 2018, south region, Ethiopia. The data was collected by structured questionnaire through face to face interviewing technique and observations were done. Fourteen providers participated in EmONC knowledge assessment. All the data were collected using standard tools which were modified in to country context and descriptive statistics were used.

Result: There was 57 full time providers working in the labour ward and only eight were midwifes. None of the Primary health care facilities had functional operating oxygen source. Only $15 \%$ and $20 \%$ of primary health care facilities were reliable access to telephone and clean water access. Majority of the provider had poor knowledge on how to manage postpartum hemorrhage and labour through using partograph.

Conclusion and Recommendation: Shortage of essential drugs, medical equipment, midwives, poor knowledge and skill of health care provider and lack of clean water and electricity had influence on service performance of EmONC in Gedeo Zone.

\section{Background}

Approximately 303,000 women die during pregnancy and childbirth each year, and millions more experience severe adverse consequences [1]. Furthermore, sub-Saharan Africa is the hardest hit region in the world, followed by Southern Asia; together they account for more than $80 \%$ of maternal and under-five deaths [2]. Globally, efforts to reduce deaths among women from complications related to pregnancy and childbirth have been less successful than other areas of human development. On average, each day around 1,500 women die from complications related to pregnancy and childbirth. The Ethiopian government was one of the first in Africa to make a strong commitment to the Milliunm development goals (MDG); reaching each of the MDG targets is central to its national development strategy. Meeting the MDG 5 target however would mean reducing its MMR by three-quarters to 218/100,000 live births by 2015 from the early 1990's estimate of 871 [3]. Providers skilled in emergency obstetric and newborn care (EmONC) services are essential, particularly in countries with a high burden of maternal and newborn mortality [3]. Emergency Obstetric and Neonatal Care (EmONC) is a cost-effective priority intervention to reduce maternal and neonatal morbidity and mortality in poor resource settings. Basic EmONC alone can avert 40\% of intrapartum related 
neonatal deaths and a significant proportion of maternal mortality The lack of skilled personnel, availability of essential medicines, unsafe abortions among others have contributed significantly to the high burden of maternal deaths in Africa. A focus on these factors is critical to Africa's vision of ending preventable maternal deaths by 2030 [3].

A set of seven key obstetric services, or "signal functions," has been identified as critical to basic emergency obstetric and newborn care (EmONC): administration of Parenteral antibiotics; administration of parenteral anticonvulsants; administration of parenteral uterotonic, removal of retained products (manual vacuum aspiration); assisted vaginal delivery; manual removal of the placenta; and resuscitation of the newborn. However, little is known about service of basic emergency obstetrics and newborn care in Gedeo zone, Therefore the aim of this study was to asses Current Evidence's on Basic Emergency Obstetric and Newborn Care in Primary Health Care unit of Gedeo zone, South Ethiopia, 2017.

\section{Methods and Materials}

\section{Study Area and period}

Gedeo zone is found in south nation nationalities and people region (SNNPR) and the capital city is Dilla which is found $84 \mathrm{~km}$ from Hawassa city which is administrative city of SNNPR and lies $394 \mathrm{Km}$ South of Addis Ababa which is the capital city of Ethiopia. The altitude of Dilla is $1765 \mathrm{~m}$ above sea level. Gedeo zone has a total of six woreda and two towns. In this zone there is one general hospital, two district hospital, 36 PHC and 146 health posts. This study was conducted from September -January 2018 G.C.

\section{Study Population}

Twenty randomly selected primary health care facilities of Gedeo zone.

\section{Inclusive Criteria}

a) Randomly Selected primary health care facilities with EmONC trained providers and willing to participate in the study.

\section{Exclusive Criteria}

a) Health posts

b) Those health centers lack EmONC trained personnel

\section{Operational Definition}

Knowledgeable: Are those health care providers who score 6 and more out of 10 maternal related questions and 3 and more out of 6 new born related questions.

Competent: Are those health care provides who demonstrate more that $50 \%$ of the required preliminary for the respective skill on diagnosis and management of labour, bleeding after childbirth, and skill scores on neonatal resuscitation.

Achieved the Seven Signal Function: are those PHC which perform at least 5 out of 7 including administration of parenteral antibiotics, administration of parenteral uterotonic drugs, manual removal of placenta, assisted vaginal delivery, and immediate new born care.

\section{Study Design}

Institutional based cross-sectional studies were used to collect the data to assess the current evidence on EmONC at PHC of Gedeo zone, SNNPR, 2018.

\section{Sampling Procedure}

Out of six Woreda and two town administration in Gedeo zone, the four Woreda were selected and one town administration was selected using simple random sampling. Then, the total number of PHC was allocated to each Woreda proportionate to the number PHC. A total of twenty PHC selected.

\section{Method of Data Collection}

Data collection methods include interviews with providers, health center head and facility observations. The principal investigator collected all the data between Sep to Jan 2018. Trained professionals did the data collection in PHC in Gedeo zone. Standard data collection tools were used based on national context.

Three major areas were assessed:

a) Identification of facility and infrastructure, using observation and interviewing

b) Human recourses,

c) Providers knowledge and skill for maternal and newborn care; 40 providers were interviewed to assess their knowledge in diagnosing and managing normal labour, PPH and neonatal conditions.

Providers were also asked if they ever received EmONC training and the interviewed providers were selected based on their presence on the date the PHC were visited with random selection in 2018.

\section{Data Quality Assurance}

The principal investigator was checked $5 \%$ questioner in Dilla town PHC which was not included in the actual study one week prior to the actual data collection period. During data collection, both principal investigator and data collectors themselves where be checked data for its completeness and missing information at each point. Furthermore, data were checked during entry into the computer.

\section{Data Analysis}

Data first was be cleared and entered into computer using SPSS 16 version for analysis. The univariate analysis such as percentage and frequency distribution of different characteristics of the questionnaire was analyzed.

\section{Results}

\section{Human Resource}

There were 57 full time providers working in the labour ward in the 20 PHC with a staffing level of minimum 1 and a maximum 4. The midwives outnumber the nurses ( $40 \%$ vs. $35 \%$ ). There was a total of 39 obstetric beds and 43 delivery couches, and the total number of deliveries attended in the $20 \mathrm{PHC}$ in the month preceding the survey was 386, which ranged from 7 to 17 (Figure 1). 


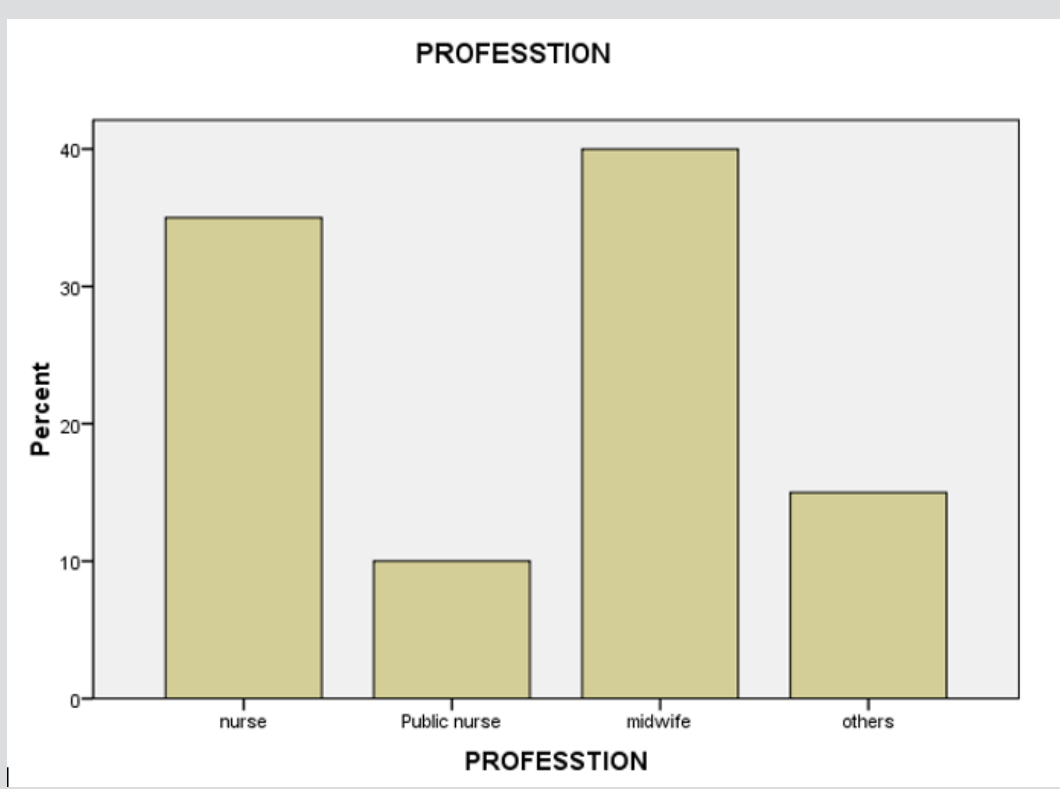

Figure 1: Proportion of providers working in the labour ward in $20 \mathrm{PHC}$ in the Gedeo zone2018.

\section{Infrastructure Service Availability}

Only $15 \%$ and $20 \%$ of the PHC were having reliable access to telephone and clean water access. All the PHCs had a formal fee waiver system and were providing maternal and newborn care free of charge. $30 \%$ of PHC provide pharmacy and laboratory service 24 hours. Regarding availability of electricity $40 \%$ of PHC were access to interrupted electric supply. None of the Primary health care facilities had functional operating oxygen source. $80 \%$ of PHC had functional toilet.

\section{Availability of Essential Drug and Medical Equipment}

$40 \%$ of the PHC had sphygmomanometer in their MCH unit where as $55 \%$ of the unit had thermometer. All PHC had Fetoscope and measuring tape in their unit. $85 \%$ of the PHC had utero-tonic drugs and $25 \%$ of the PHC had IV-anti-biotic. $35 \%$ of the PHC had radiator heater and only $25 \%$ of the centers had manual vacuum aspiration set. Regarding vacuum extraction $20 \%$ of the PHC had it.

\section{Performance of the Seven-Signal Function in Primary Health Care Facilities}

All PHC perform new born resuscitation but none of the PHC achieved all the seven-signal function of EMONC. $15 \%$ of the PHC performed vacuum extraction. Regarding anti-convulsion drugs $20 \%$ of the PHC provide either magnesium or diazepam the rest doesn't. Majority of them $85 \%$ of provide utero- tonic drugs. $60 \%$ of facilities performed manual removal of the placenta, $15 \%$ of PHC performed Manual vacuum aspirations Table 1.

Table 1: Performance of the seven signal functions of EMONC in PHC of Gedeo zone 2017.

\begin{tabular}{|c|c|c|c|c|c|c|c|c|}
\hline S. No & Name of HCs & $\begin{array}{l}\text { Parenteral } \\
\text { anti-biotic }\end{array}$ & $\begin{array}{c}\text { Parenteral } \\
\text { anti- } \\
\text { convulsant }\end{array}$ & $\begin{array}{c}\text { Parenteral } \\
\text { uterotonic } \\
\text { drugs }\end{array}$ & MVA & $\begin{array}{c}\text { Vacuum } \\
\text { extraction }\end{array}$ & $\begin{array}{c}\text { Removal } \\
\text { of retained } \\
\text { placenta }\end{array}$ & $\begin{array}{c}\text { Neonatal } \\
\text { recustation }\end{array}$ \\
\hline 1 & Herde & $\sqrt{ }$ & $x$ & $\sqrt{ }$ & $x$ & $\sqrt{ }$ & $\times$ & $\sqrt{ }$ \\
\hline 2 & Adado & $x$ & $x$ & $\sqrt{ }$ & $\sqrt{ }$ & $x$ & $\sqrt{ }$ & $\sqrt{ }$ \\
\hline 3 & Udo & $x$ & $x$ & $\sqrt{ }$ & $\sqrt{ }$ & $x$ & $\sqrt{ }$ & $\sqrt{ }$ \\
\hline 4 & Bule & $x$ & $x$ & $\sqrt{ }$ & $x$ & $x$ & $\sqrt{ }$ & $\sqrt{ }$ \\
\hline 5 & Sisota & $\sqrt{ }$ & $x$ & $x$ & $x$ & $x$ & $\sqrt{ }$ & $\sqrt{ }$ \\
\hline 6 & Gersea & $x$ & $x$ & $\sqrt{ }$ & $x$ & $x$ & $x$ & $\sqrt{ }$ \\
\hline 7 & Kelicha & $x$ & $\sqrt{ }$ & $\sqrt{ }$ & $x$ & $x$ & $\sqrt{ }$ & $\sqrt{ }$ \\
\hline 8 & Biloya & $x$ & $x$ & $\sqrt{ }$ & $x$ & $x$ & $\sqrt{ }$ & $\sqrt{ }$ \\
\hline 9 & Hassa haro & $\sqrt{ }$ & $x$ & $\sqrt{ }$ & $x$ & $x$ & $\sqrt{ }$ & $\sqrt{ }$ \\
\hline 10 & Haruo & $x$ & $x$ & $\sqrt{ }$ & $x$ & $x$ & $x$ & $\sqrt{ }$ \\
\hline 11 & Bilya & $x$ & $x$ & $\sqrt{ }$ & $x$ & $x$ & $\sqrt{ }$ & $\sqrt{ }$ \\
\hline 12 & Moraliywe & $x$ & $\sqrt{ }$ & $\sqrt{ }$ & $x$ & $x$ & $\sqrt{ }$ & $\sqrt{ }$ \\
\hline 13 & Haruo bedama & $x$ & $x$ & $\sqrt{ }$ & $\sqrt{ }$ & $\sqrt{ }$ & $x$ & $\sqrt{ }$ \\
\hline 14 & Banko tatitu & $x$ & $\times$ & $\times$ & $\sqrt{ }$ & $\sqrt{ }$ & $\sqrt{ }$ & $\sqrt{ }$ \\
\hline 15 & Worika & $x$ & $x$ & $\sqrt{ }$ & $x$ & $x$ & $\sqrt{ }$ & $\sqrt{ }$ \\
\hline
\end{tabular}




\begin{tabular}{|c|c|c|c|c|c|c|c|c|}
\hline 16 & Hanku & $\sqrt{ }$ & $\times$ & $\sqrt{ }$ & $\times$ & $\times$ & $\sqrt{ }$ \\
\hline 17 & Konga & $\sqrt{ }$ & $\times$ & $\times$ & $\times$ & $\sqrt{ }$ & $\sqrt{ }$ \\
\hline 18 & Moknisa & $\sqrt{ }$ & $\times$ & $\sqrt{ }$ & $\times$ & $\times$ & $\sqrt{ }$ & $\sqrt{ }$ \\
\hline 19 & Shifo & $\times$ & $\times$ & $\sqrt{ }$ & $\times$ & $\times$ & $\times \sqrt{ }$ \\
\hline 20 & Kcorso & $\times$ & $\times$ & $\sqrt{ }$ & $\times$ & $\times$ & $\times$ \\
\hline & & & & & & & \\
\hline
\end{tabular}

\section{Providers' Knowledge}

In this study all participants reported that they did know about the component of active Management of Third Stage Labour (AMTSL). Providers mean score on diagnosing PPH was 2.25 out of 6 correct answers. Six providers only knew four of the six preliminary steps of neonatal resuscitation. The mean skill score on how to resuscitate a neonate with bag mask was 2.5 out of 4 correct answers. Providers mean score on providing FANC was 2.35 out of 3 correct answers Table 2 .

Table 2: Providers mean knowledge scores on diagnosis and management of labour, bleeding after childbirth, and skill scores on neonatal resuscitation in 2018.

\begin{tabular}{|c|c|c|}
\hline Question & $\mathrm{N}=40100 \%$ & $\mathrm{~N}=40$ Mean \\
\hline $\begin{array}{l}\text { How do you know when a pregnant woman is in labour? } \\
\text { Out } 4 \text { correct answer if they response } 3\end{array}$ & 78.75 & 3.15 \\
\hline $\begin{array}{l}\text { What do you monitor when a woman is in labour? } \\
\text { Out of } 9 \text { correct answer if they response } 5\end{array}$ & $45 \%$ & 4.05 \\
\hline $\begin{array}{l}\text { What are the steps of AMTSL? } \\
\text { Out of } 3 \text { correct answers if they response } 3\end{array}$ & 100 & 3.00 \\
\hline $\begin{array}{l}\text { What do you look for when a woman arrives with or develops heavy bleeding after birth? } \\
\text { Out of } 6 \text { correct answers if they response } 3\end{array}$ & $44 \%$ & 2.25 \\
\hline $\begin{array}{l}\text { What do you do when a woman arrives with or develops heavy bleeding after birth? } \\
\text { Out of } 6 \text { correct answers if they response } 3\end{array}$ & $46.6 \%$ & 2.4 \\
\hline $\begin{array}{l}\text { If resuscitate a neonate with bag mask, what do you do? } \\
\text { Out } 4 \text { correct answers if they response } 3\end{array}$ & $60 \%$ & 2.4 \\
\hline
\end{tabular}

\section{Discussion}

In the health sector in general, and in maternal health in particular, health care professionals are at the heart of the success of EmONC interventions. The performance of any health system, and thus the improvement of a population's health, depends on the productivity, competence, availability and responsiveness of health professionals [4]. Regarding human resource this study revealed that there is a critical shortage of health-care providers especially midwifes in the zone. Only eight midwives were available in twenty PHC. This shortage was similar with the World Health Organization (WHO) report that 36 of the 57 countries facing chronic human resource shortages in the health sector are in SSA and that only 2.6 and 12.0/10,000 of physicians and nursing/midwifery personnel [5]. This shortage is due to lack of competent as well as qualified midwifes plus in some case there is financial constrain to recruit the midwife in south region as well as in country. Adequate availability of infrastructure is a crucial prerequisite for effective MNH services delivery.

It is extremely difficult for health care provider to offer quality services without physical space (rooms), beds for patients and source of electricity and running water. Similarly, functional mode of transport and communication systems is essential for timely and quick referral of emergency patients to a next higher level of health care facility ( $9 \& 10)$. So, this study revealed that the service provision related with labor and delivery were $100 \%$ (24/7). Only $15 \%$ and $20 \%$ respectively of the HCs were having reliable access to telephone and clean water access. This finding is not consistent with Study in Addis Ababa stated that $100 \%$ of the HCs were having reliable access to telephone and clear water while these were $24 \%$ and $44 \%$ respectively in 2008 [6]. This is due to most of the PHC were found in most remote part of the zone as well the region and the government were plan to access those in GDP two [7]. This study also revealed that $40 \%$ of the health centers were access to the electricity even which not available 24 hours.

Study in Somali is revealed that Only 1 out of 6 MCHs (Waaberi) had both electricity and water supply. Whereas 2 out of $6 \mathrm{MCHs}$ (Horseed and Hagi Abdulhi), had neither electricity nor water supply. Gambool quite a busy MCH did not have running water or hand washing facilities. Staff used main tap outside for hand washing, however electricity was available $24 \mathrm{hrs}$. The remaining 2 MCH centres (South Galkayo and IDP Galkayo) had either electricity or water supply $[7,8]$. This study revealed that Ambulance services were available in $100 \%$ of the PHCU through calling system from the Woreda as well from Woreda administration plus from red cross if they avail in the Woreda. This is inconsistent with study carried in Addis Ababa. Ambulance services were available in 50\% of the HCs in 2013 while the remaining HCs were relaying on ambulances from the fire department (command post) especially off working hours. In 2008, only $34 \%$ HCs reported to have access to ambulance services [9].

Similar study in Somalia revealed all the health facilities did not have any means of transport facility for referral cases. Patients' families were responsible to make such arrangements on their own. Studies in Uganda state a car ambulance were available at $46 \%$ of 
the facilities [10]. This is due to the region as well the zone gives more attention to avoid one of cause for maternal mortality that is due to delay to reach to health institution. So that at least their while is one ambulance in woreda. Regarding payment system our study investigate that all the PHC had a formal fee waiver system and were providing maternal and newborn care free of charge. This is consistent with study in Somalia revealed almost all the facilities surveyed did not require formal payment before consultation especially in case of emergency. Nevertheless, women. In general, no payment was required to get routine medicines for ANC/PNC and EPI service [11]. Our study revealed availability of vital sign equipment only $40 \%$ of the health centers have their own sphygmomanometer in their MCH unit where as 55\% of the unit have thermometer. Study in Tanzania state the availability of clinical equipment was generally lower: $61 \%$ of facilities had a blood pressure machine, $70 \%$ had an infant weighing scale and $57 \%$ had a speculum $[12,13]$.

Regarding essential drugs this study revealed all the PHC have intravenous fluids whereas more than half of the health centers have no anti-convulsant $.85 \%$ of the health centers have utero-tonic drugs and $25 \%$ of the health centers have IV-anti-biotic. $35 \%$ of the health center have radiator heater and only $25 \%$ of the centers have MVA set. Regarding vacuum extraction $20 \%$ of the PHCU have this and none of the health centers have complete instrument processing as well waste disposable blanket [14]. Study in Tanzania stated in terms of hand washing facilities (85\%). Oxytocin, which is used for bleeding control, was found in very few facilities (28\%); surprisingly, Ergometrine, which is now not recommended for bleeding control, was found to be present in seven (39\%) facilities [15]. Despite its importance in the initial stabilization of women who experience obstetric emergencies, IV infusions, Ringer lactate and normal saline were present in only half of the facilities. Study in Malawi stated that all the facilities did not have postnatal care monitoring equipment like sphygmomanometer and thermo meters in their maternity departments. In addition, guide- lines and teaching aids for postnatal care were not avail-able in all the facilities [16].

Regarding provider knowledge this study revealed $100 \%$ of the participants reported that they did know about Active Management of Third Stage Labour (AMTSL) all. Providers mean score on diagnosing PPH was 2.25 out of 6 correct answers (46.6\%) and the mean skill score on how to resuscitate a neonate with bag mask was 2.5 out of 4 correct answers (60\%). This is consistent with Study in Addis Ababa stated that most of the providers who participated in both surveys reported to have insufficient knowledge in diagnosing postpartum hemorrhage (PPH) and birth asphyxia as well as poor skills in neonatal resuscitation. Study in Malawi state the worstanswered questions were 'management of a baby who does not breathe spontaneously' (which only 35\% answered correctly) and 'management of a baby with low Agar scores at 1 minute', which $58 \%$ answered correctly, whilst $23 \%$ gave potentially lifethreatening responses, including 4 respondents (8\%) who said no action was required and 2 respondents (4\%) who said they did not know what to do [5,17].
Responses demonstrated a widespread lack of awareness of danger signs in a newborn infant and a limited understanding of simple lifesaving procedures, such as stimulation of the newborn, skin-to-skin contact and early initiation of breastfeeding as well as use of oxygen and cardio-pulmonary-resuscitation [18]. Regarding the achievement of seven signal function this study revealed that $100 \%$ of the PHCU perform new born resuscitation this is inconsistent with study in Uganda revealed actions to take if a newborn failed to breathe were mentioned by $62 \%$.This is due to one the case were common and the provider receive special training. Whereas $25 \%$ of the PHCU perform vacuum extraction and only $15 \%$ of the health centers have IV anti-biotic. Regarding anti-convulsant drugs $40 \%$ of the health centers provide either magnesium or diazepam the rest doesn't. Majority of the PHCU 85 $\%$ of provide utero- tonic drugs. Regarding manual removal of the placenta $65 \%$ of the PHCU this signal function this is consistent with study in Uganda Manual removal of the placenta had also been done by $62 \%$ of the staff [19]. Manual vacuum aspirations only $20 \%$ of the PHCU perform this signal function.

\section{Conclusion}

Several shortfalls in emergency obstetric and newborn care have been identified by this study in Gedeo zone south region. This study showed there is difference problem that can influence for successful practice of EmONC in the zone. In general, this zone has major shortage on midwifes and the majority of the care provider have poor knowledge on diagnosing and managing labour by using partograph and managing women with bleeding after child birth. In addition, majority of the health center have no access for clean water and telephone line so that which make difficult to avoid delay and to practice infection prevention and patient safety. More than half of the health centers lack essential drugs like IV-antibiotics and Anti-convulsant drugs. Additionally, only very few health centers have vacuum extraction as well MVA sets. The findings of this study revealed that Lack of essential drugs as well medical equipment, shortage of midwifes poor knowledge and skill of health care provider and lack of clean water and electricity to be influence the EmONC at the Zone. Therefore, the actual trend of EmONC is diminishing, that is the majority of the health centers have not performed EmONC as needed.

\section{Ethical Consideration}

Letter of permission was obtained before the beginning of data collection from Gedeo zone health bureau. Permission letter were provided to select Woreda for proceeding data collection. After that participants oriented about the purpose and procedure of data collection, and that confidentiality and privacy ensured. It is also cleared that participation fully based on the willingness of participants using written consent.

\section{Acknowledgement}

First of all, I would like to thank the supreme Lord for helping me to attain such a success, addition to Dilla university Referral Hospital and health science college staffs for their great help and for Gedeo zone health department and for respective Woreda. 


\section{References}

1. (2015) WHO Trends in maternal mortality: 1990 to 2015 . WHO/UNICEF, Countdown to 2015 Report.

2. (2015) UN IGME Levels and Trends in Child Mortality Report 2015. WHO, Trends in maternal mortality: 1990 to 2015

3. George Schmid (2005) The Lancet's neonatal survival series. The Lancet 365(9474): 1845.

4. (2012) Federal demographic republic of Ethiopia maternal and child health package.

5. Lawn JE, Kerber K, Enweronu-Laryea C, Cousens S (2010) 3.6 Million Neonatal Deaths- What Is Progressing and What Is Not? Seminars in Perinatology 34(6): 371-386.

6. Miller S, Cordero M, Coleman AL, Figueroa J, Brito-Anderson S, et al. (2003) Quality of care in Institutionalized deliveries. The paradox of the Dominican Republic. Int J Gynaecol Obstet 82: 89-103.

7. (2014) World Health Organization, UNFPA, UNICEF, AMDD Monitoring emergency obstetric care: a handbook. Geneva: WHO.

8. WHO (2005) Make every Mother and Child Count. Geneva: World Health Organization.

9. Admasu K, Haile-Mariam A, Bailey P (2011) Indicators for availability, utilization, and quality of emergency obstetric care in Ethiopia, 2008. Int J Gynaecol Obstet 115(1): 101-105.

10. Rigoli F, Dussault G (2003) The interface between health sector reform and human resources in health. Human Resources for Health 1: 9.

\section{ISSN: 2574-1241}

DOI: 10.26717/BJSTR.2019.17.003005

Rekiku Fikre. Biomed J Sci \& Tech Res

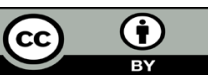

This work is licensed under Creative Commons Attribution 4.0 License

Submission Link: https://biomedres.us/submit-manuscript.php
11. Graham WJ, Bell J, Bullough CHW (2001) Can skilled attendance at delivery reduce maternal mortality in developing countries. Studies Health Serv Organ Policy 17: 97-130.

12. Miller S, Cordero M, Coleman AL, Figueroa J, Brito-Anderson S, et al. (2003) Quality of care in Institutionalized deliveries. The paradox of the Dominican Republic. Int J Gynaecol Obstet 82: 89-103.

13. Lohr K (1990) Institute of Medicine, author. Medicare: A Strategy for Quality Assurance. Washington DC, USA: The National Academies Press.

14. WHO (2006) Working together for health. Geneva: World Health Organization.

15. Borghi J, Ensor T, Somanathan A, Lissner C, Mills A (2006) Mobilising financial resources for maternal health. Lancet 368(9545): 1457-1465.

16. Rogo KO, Oucho J, Mwalali P (2006) Maternal mortality. In Disease and Mortality in Sub-Saharan Africa. ( $2^{\text {nd }}$ edn.). Edited by Jamison DT, Feachem RG, Makgoba MW, Bos ER, Baingana FK, Hofman KJ, Rogo KO. Washington DC: World Bank.

17. (2013) Ifakara Health Institute. Tanzania Service Availability and Readiness Assessment (SARA) 2012. Dar es Salaam: Ifakara Health Institute.

18. (2012) UNICEF Levels \& Trends in Child Mortality: Estimates Developed by the UN Inter-agency Group of Child Mortality Estimation. World Health Organization, the World Bank, United Nations.

19. (2012) WHO, UNICEF, UNFPA Trends in Maternal Mortality: 1990 to 2010. Washington, DC: The World Bank.

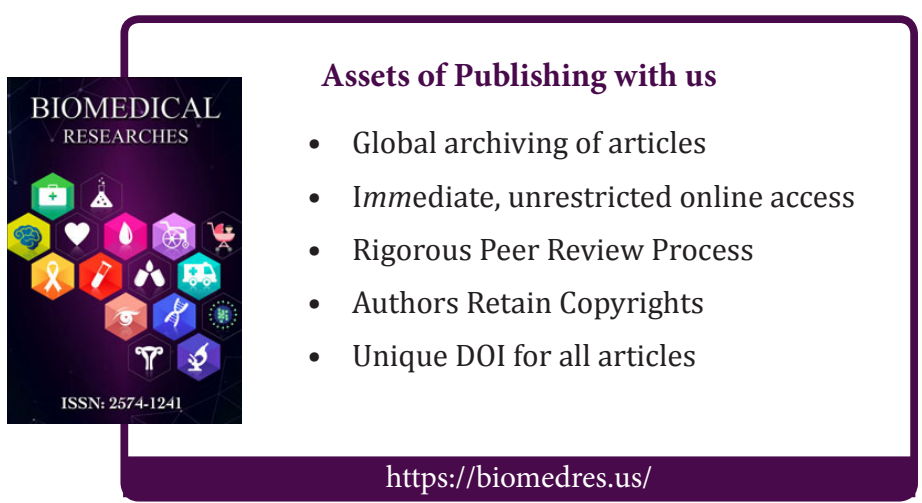

